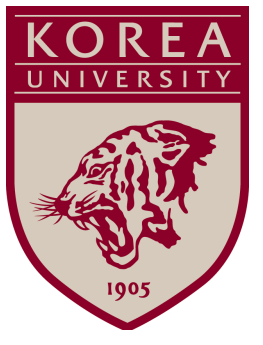

Discussion Paper Series

No. 1705

September 2017

\title{
Optimal Licensing of Technology in the Face of (Asymmetric) Competition
}

Cuihong Fan Byoung Heon Jun Elmar G. Wolfstetter 


\title{
Optimal Licensing of Technology in the Face of (Asymmetric) Competition*
}

\author{
Cuihong Fan \\ Shanghai University of Finance and Economics \\ Byoung Heon Jun ${ }^{\dagger}$ \\ Korea University \\ cuihongf@mail.shufe.edu.cn \\ bhjun@korea.ac.kr \\ Elmar G. Wolfstetter \\ Humboldt-University at Berlin and Korea University \\ elmar.wolfstetter@rz.hu-berlin.de
}

June 14, 2017

\begin{abstract}
We reconsider the optimal licensing of technology by an incumbent firm in the presence of multiple potential licensees. In a first step we show that competition among potential licensees has a drastic effect on optimal two-part tariff contracts. We then introduce more general mechanisms and design a dynamic mechanism that extracts the maximum industry profit while reducing the potential licensees' payoff to the minimum level that they can assure themselves. That mechanism can be viewed as a generalized "chutzpah" mechanism, generalized because it employs royalties to maximize the industry profit. It awards licenses to all firms and prescribes maximum permitted royalty rates plus positive fixed fees.
\end{abstract}

KEYWORDS: Patent licensing, innovation, optimal contracts, dynamic mechanisms.

JEL ClassificATIONS: D21, D43, D44, D45.

\section{Introduction}

In the present paper we examine optimal patent licensing by an incumbent firm that interacts with potential licensees in a downstream oligopoly market. We relax the standard assumptions that there is only one potential licensee, that the licensor issues only one license, that potential licensees have the same unit cost, that demand is linear, and that license contracts are simple take-it-or-leave-it offers.

Prior to licensing firms have different unit costs that are common knowledge. The licensor owns a superior technology; its transfer reduces licensees' unit cost to the licensor's cost level. Firms compete in a downstream Cournot oligopoly with homogeneous goods. License contracts are either simple two-part-tariffs, that prescribe a combination of per-unit royalty rates and fixed fees, or more complex dynamic contracts.

\footnotetext{
${ }^{*}$ Research support by Korea University (Grant: K1701281) and the National Natural Science Foundation of China (Grant: 71371116) is gratefully acknowledged.

${ }^{\dagger}$ Corresponding author. Department of Economics, Korea University, 145 Anam-ro, Seongbuk-gu, Seoul, 02841, Korea.
} 
In a first step, we analyze the case when only one license is issued, which plays a prominent role in the literature. We show that the optimal two-part tariff changes drastically when the number of potential licensees is increased from one to two and again from two to more. We also show that the licensor can increase his payoff if he employs more general dynamic contracts.

In a second step we relax the assumption that the licensor issues only one license. We design a twostage dynamic mechanism that awards licenses to all licensees and prescribes maximum royalty rates equal to firms' cost reductions together with positive fixed fees. This mechanism makes the first-round contract offers contingent upon its acceptance by other firms, and, in the event when at least one licensee rejects the first-round offer, rewards those who accepted it.

We show that this mechanism is optimal in the sense that its application makes the licensor's payoff equal to the maximum industry profit that can be achieved by two-part tariffs, minus the minimum payoffs that licensees can assure themselves. This is why it is essentially a generalized "chutzpah" mechanism; generalized, because it maximizes the surplus by controlling outputs through royalties (and thus is more profitable than the original chutzpah mechanism). We also show that it applies even in more general models, when cost profiles are such that licensing may crowd out some firms from the market.

The literature on patent licensing by an incumbent or inside firm was initiated by Wang (1998). He showed that there is a sharp distinction between the licensing of a non-drastic innovation by an outside patent holder, who is not a player in the potential licensee's market game, and an incumbent patent holder who is a competitor in the product market of potential licensees. Whereas outside innovators are advised to auction patent licenses to a limited number of licensees, inside patent holders are advised to employ output based royalty contracts without fixed fees. ${ }^{1}$ However, his analysis was carried out in the framework of a duopoly with one potential licensee, a particular cost profile, and linear demand.

The case of licensing in a duopoly was further pursued in numerous contributions. Among the more recent contributions, San Martín and Saracho (2010) compare output based vs. ad valorem royalty contracts. Niu (2013) considers profit-share licensing and proves the equivalence of profitshare and per-unit royalty licensing, allowing for non-linear demand. Heywood, Li, and Ye (2014) introduce incomplete information and confirm the optimality of pure royalty licensing in a binary model with a particular cost profile. Fan, Jun, and Wolfstetter (2017) consider a general model of incomplete information that allows for all possible cost profiles and a continuum of types and show that it is generally optimal to employ two part tariffs rather than pure royalty contracts.

In another branch of the literature, product differentiation was introduced in games of complete information, for example, in Faulí-Oller, Gonzàlez, and Sandonís (2013), Colombo and Filippini (2015), and Niu (2017), and in games of incomplete information in Fan, Jun, and Wolfstetter (2016) who focus on the licensor's optimal information disclosure policy.

The papers that are most closely related to the present inquiry are Kamien and Tauman (2002), Sen and Tauman (2007), and Creane, Ko, and Konishi (2013) who pioneered the analysis of the role of competition between potential licensees. Kamien and Tauman (2002) generalize Wang (1998) to multiple potential licensees and multiple licenses and show that pure royalty licensing is superior for an incumbent inventor to both auctions or fixed-fee licensing if the magnitude of the

\footnotetext{
${ }^{1}$ However, Giebe and Wolfstetter (2008) and Fan, Jun, and Wolfstetter (2013) show that an outside innovator can increase his payoff by supplementing license auctions with per-unit royalty contracts for those who lose the auction, and Poddar and Sinha (2010) and Fan, Jun, and Wolfstetter (2017) show at different levels of generality that an inside innovator can generally increase his payoff by employing two-part tariffs rather than pure royalty contracts.
} 
invention is not too small. Sen and Tauman (2007) consider optimal two-part tariffs in the presence of multiple potential licensees and multiple licenses. They assume that all potential licensees have the same unit cost and linear demand and find that it is generally optimal to employ both royalty rates and fixed fees and award licenses to almost all firms. Creane, Ko, and Konishi (2013) assume that the licensor awards one license to one among several potential licensees. They focus on the question whether the optimal selection of licensee maximizes the joint profit of licensee and licensor and whether it maximizes welfare, generalizing earlier contributions by Katz and Shapiro (1985) and La Manna (1993), and explore whether awarding the license through a combinatorial auction may improve the efficiency of the allocation by internalizing the externality imposed on non-licensees.

The present paper complements these contributions. The main value added is that we allow for general demand functions and asymmetries between firms, introduce complex dynamic license mechanisms, allow the licensor to award multiple licenses, and design an optimal license mechanism that allows the licensor to extract the maximum surplus while reducing licensees' payoffs to the minimum they can assure themselves.

The plan of the paper is as follows: In Section 2 we introduce the model and explain the constraints on license contracts imposed by antitrust rules. In Section 3 we consider the case when one license is awarded to one of several potential licensees. We solve the optimal two-part tariff contract, characterize the optimal allocation rule, and then introduce more complex dynamic contracts that are more profitable for the licensor. In Section 4 we generalize by allowing for multiple licenses. We design a globally optimal license mechanism and show that it awards licenses to all potential licensees and allows the licensor to extract the maximum surplus. We close with a brief Discussion in Section 5.

\section{Model}

Consider a dynamic licensing game played between an incumbent firm that owns a superior technology and $n$ competitors that operate in the same product market. In the first stage the licensor offers license contracts in the form of two-part tariffs that prescribe royalty rates per output unit, $r_{i}$, and fixed fees, $f_{i}$, which licensees either accept or reject. After observing their rivals' acceptance decisions and contracts, in the second stage firms play a Cournot market game.

Firms are indexed by $i \in N_{+}:=\{0,1, \ldots, n\}$, where firm 0 is the licensor and firms $N:=\{1, \ldots, n\}$ the potential licensees. Firms are ordered by their prior efficiency. Prior to licensing, firms' unit cost profile is $c^{0}=\left(c_{0}, c_{1}, \ldots, c_{n}\right)$ with $c_{0}<c_{1} \leq c_{2} \leq \ldots \leq c_{n}$. Licensing to firm $i \in N$ reduces that firm's unit cost from $c_{i}$ to $c_{0}$ and its effective unit cost to $c_{i}\left(r_{i}\right):=c_{0}+r_{i}{ }^{2}$

The payoff functions of the oligopoly subgames are: $\pi_{i}\left(q_{i}, q_{-i}\right)=\left(P(Q)-c_{i}\left(r_{i}\right)\right) q_{i}$, for $i \in N$ and $\pi_{0}\left(q_{0}, q_{-0}\right)=\left(P(Q)-c_{0}\right) q_{0}$, with $Q:=\sum_{i \in N_{+}} q_{i}$. There $q_{i}$ denotes the output of firm $i, q_{-i}$ the output vector of all firms other than $i$, and $P(Q)$ the inverse demand function which is decreasing and concave. Also, we denote the equilibrium outputs induced by licensing with the effective unit cost profile $c(r):=\left(c_{0}, c_{1}+r_{1}, \ldots, c_{n}+r_{n}\right)$ by $q_{i}(c(r)), Q(c(r)):=\sum_{i \in N_{+}} q_{i}(c(r))$, and, with slight abuse of notation, the associated equilibrium profits by $\pi_{i}(c(r))$.

The licensor maximizes his payoff, which consists of his own profit plus license income. He offers either take-it-or-leave-it contracts, which individual licensees either accept or reject, or more complex dynamic contracts that make the terms of the contract contingent on the acceptance decisions

\footnotetext{
${ }^{2}$ Katz and Shapiro (1985) call this a "complete" technology transfer.
} 
of all licensees, to which we refer as "contingent mechanisms". The exact meaning of these terms will be explained below.

License contracts are regulated by antitrust authorities that interfere if they suspect collusive schemes that are geared to raise the equilibrium price. As usual in the literature, we capture these regulations by requiring that royalty rates must be nonnegative and cannot exceed licensees' cost reductions: ${ }^{3}$

$$
r_{i} \in R_{i}:=\left\{r_{i} \in \mathbb{R}_{+}^{n} \mid r_{i} \leq c_{i}-c_{0}\right\} \quad \text { (antitrust constraints). }
$$

The cost profiles are such that no firm is ever crowded out of the market, before and after licensing. This assumption is relaxed in Section 4.

\section{Optimal licensing if one license is offered}

The bulk of the literature on licensing technology by an inside patent holder assumed that the licensor offers one license to one competitor with whom he interacts in a duopoly market. In that case, the optimal license contract is a pure royalty contract without fixed fee that prescribes the maximal permitted royalty rate equal to the licensee's cost reduction (see Shapiro (1985) and Wang (1998)). ${ }^{4}$

However, this result is not robust. As a first test, in this section, we increase the number of potential licensees to $n \geq 2$, while maintaining the assumption that only one license is offered. This variation has a drastic impact on the optimal licensing scheme.

For convenience, denote the cost profile that applies if the license is awarded to firm $i \in N$ by $c^{i}:=\left(c_{0}, c_{1}, \ldots, c_{i-1}, c_{0}, c_{i+1}, \ldots, c_{n}\right)$ and indicate the allocation of the license by the induced cost profile. With slight abuse of notation, we also define the associated effective cost profile $c^{i}\left(r_{i}\right):=$ $\left(c_{0}, c_{1}, \ldots, c_{i-1}, c_{0}+r_{i}, c_{i+1}, \ldots, c_{n}\right)$, and $q_{j}\left(r_{i}\right):=q_{j}\left(c^{i}\left(r_{i}\right)\right), Q\left(r_{i}\right):=\sum_{j \in N_{+}} q_{j}\left(r_{i}\right)$.

In line with the literature, we (first) consider the class of static take-it-or-leave-it mechanisms that prescribe a two-part tariff contract, $\left(r_{i}, f_{i}\right)$, to one designated licensee, $i$. The optimal mechanism determines the optimal contract and allocation of license that maximize the licensor's payoff: $\Pi_{0}=$ $\pi_{0}\left(c^{i}\left(r_{i}\right)\right)+r_{i} q_{i}\left(c^{i}\left(r_{i}\right)\right)+f_{i}$.

Proposition 1 (Optimal take-it-or-leave-it mechanism). The optimal take-it-or-leave-it mechanism is the pure fixed-fee contract: $\left(r_{i}, f_{i}\right)=\left(0, \pi_{i}\left(c^{i}\right)-\pi_{i}\left(c^{0}\right)\right)$, to be awarded to the firm $i$ that maximizes the increment of the joint profit of licensee and licensor. The fixed fee $f_{i}$ makes the licensee indifferent between the allocations $c^{i}$ and $c^{0}$.

Proof. 1) Suppose the license is offered to firm $i$. No matter what royalty rate is set, it is optimal to set the highest acceptable fixed fee, i.e., $f_{i}=\pi_{i}\left(c^{i}\left(r_{i}\right)\right)-\pi_{i}\left(c^{0}\right)$. Therefore, one can write the total payoff of the licensor, $\Pi_{0}$, as a function of $r_{i}$ :

$$
\begin{aligned}
\Pi_{0}\left(r_{i}\right) & =\pi_{0}\left(c^{i}\left(r_{i}\right)\right)+r_{i} q_{i}\left(c^{i}\left(r_{i}\right)\right)+\pi_{i}\left(c^{i}\left(r_{i}\right)\right)-\pi_{i}\left(c^{0}\right) \\
& =\left(P\left(Q\left(r_{i}\right)\right)-c_{0}\right)\left(q_{0}\left(r_{i}\right)+q_{i}\left(r_{i}\right)\right)-\pi_{i}\left(c^{0}\right) .
\end{aligned}
$$

\footnotetext{
${ }^{3}$ For a more detailed discussion of antitrust issues see Fan, Jun, and Wolfstetter (2017). There we also point out that the lower bound on permitted royalty rates does not completely rule out negative royalty rates. For simplicity of exposition we ignore this possibility here.

${ }^{4}$ For a proof that does not assume linearity of demand (which is usually assumed in the literature) see Footnote 6 below.
} 
It follows that the optimal $r_{i}$ maximizes the joint profit of licensor and licensee.

Using the characterization of the equilibrium outputs in the oligopoly subgames spelled out in Appendix A, the derivative of the licensor's payoff with respect to $r_{i}$ is equal to:

$$
\begin{aligned}
\partial_{r_{i}} \Pi_{0}\left(r_{i}\right) & =\left(q_{0}\left(r_{i}\right)+q_{i}\left(r_{i}\right)\right) P^{\prime}\left(Q\left(r_{i}\right)\right) Q^{\prime}\left(r_{i}\right)+\left(P\left(Q\left(r_{i}\right)\right)-c_{0}\right)\left(q_{0}^{\prime}\left(r_{i}\right)+q_{i}^{\prime}\left(r_{i}\right)\right) \\
& =\frac{N_{1}+N_{2}}{P^{\prime}\left(Q\left(r_{i}\right)\right)^{2}\left((n+2) P^{\prime}\left(Q\left(r_{i}\right)\right)+Q\left(r_{i}\right) P^{\prime \prime}\left(Q\left(r_{i}\right)\right)\right)} \\
\text { where } \quad N_{1} & =\left((n-2)\left(P\left(Q\left(r_{i}\right)\right)-c_{0}\right)+r_{i}\right) P^{\prime}\left(Q\left(r_{i}\right)\right)^{2}>0 \\
N_{2} & =-\left(P\left(Q\left(r_{i}\right)\right)-c_{0}\right)\left((n-1) P\left(Q\left(r_{i}\right)\right)-\sum_{j \notin\{0, i\}} c_{j}\right) P^{\prime \prime}\left(Q\left(r_{i}\right)\right)>0 .
\end{aligned}
$$

Because the denominator is negative and $N_{1}, N_{2}>0$, it follows that $\partial_{r_{i}} \Pi_{0}\left(r_{i}\right)<0$. Together with the anti-trust constraint (1) this implies that it is optimal to set $r_{i}=0$.

2) Suppose the allocation $c^{i}$ maximizes the increment of the joint profit (relative to no licensing). Then, it also maximizes the licensor's profit and vice versa, because: ${ }^{5}$

$$
\begin{aligned}
0 & <\pi_{0}\left(c^{i}\right)+\pi_{i}\left(c^{i}\right)-\left(\pi_{0}\left(c^{0}\right)+\pi_{i}\left(c^{0}\right)\right)-\left(\pi_{0}\left(c^{j}\right)+\pi_{j}\left(c^{j}\right)-\left(\pi_{0}\left(c^{0}\right)+\pi_{j}\left(c^{0}\right)\right)\right) \\
& =\pi_{0}\left(c^{i}\right)+\pi_{i}\left(c^{i}\right)-\pi_{i}\left(c^{0}\right)-\left(\pi_{0}\left(c^{j}\right)+\pi_{j}\left(c^{j}\right)-\pi_{j}\left(c^{0}\right)\right) \\
& =\pi_{0}\left(c^{i}\right)+f_{i}-\left(\pi_{0}\left(c^{j}\right)+f_{j}\right) .
\end{aligned}
$$

Evidently, it makes a drastic difference if licensee and licensor face one (or more) competitor(s).

If the coalition of licensee and licensor face no competition (i.e, if $n=1$ ), it is in their best interest to restrict the licensee's output as much as possible to bring aggregate output as close as possible to monopoly output. Because output can only be restricted indirectly by charging the licensee a royalty rate and royalty rates are constrained by antitrust rules, this is achieved by setting the highest permitted royalty rate equal to the licensee's cost reduction, i.e., $r_{1}=c_{1}-c_{0}{ }^{6}$

If the coalition of licensor and licensee face at least one competitor, it is in their best interest to weaken the competitor(s) by charging the licensee the minimal permitted royalty rate, $r=0 .^{7}$ The licensor can fully extract the licensee's gain by means of the fixed fee. Therefore, what is in the best interest of the coalition is also in the best interest of the licensor.

However, "take-it-or-leave-it" mechanisms are too restrictive. One can easily design dynamic mechanisms that are more profitable for the licensor.

Consider two-stage "dynamic mechanisms", $\left(i, j, r_{i}, f_{i}, r_{j}, f_{j}\right), i \neq j$, where:

1) In the first stage, the licensor makes the take-it-or-leave-it offer $\left(r_{i}, f_{i}\right)$ to firm $i$. If firm $i$ accepts, it gets the license with $\left(r_{i}, f_{i}\right)$.

\footnotetext{
${ }^{5}$ Assuming fixed-fee licensing, Creane, Ko, and Konishi (2013) already observed that it is optimal to award the license to the firm that maximizes the increment of the joint profit of licensor and licensee, without checking whether fixed-fee licensing is optimal.

${ }^{6}$ Formal proof: If $n=1$, the licensor's profit is equal to $\Pi_{0}\left(r_{1}\right)=\left(P\left(Q\left(r_{1}\right)\right)-c_{0}\right) Q\left(r_{1}\right)-\pi_{i}\left(c^{0}\right)$. Therefore, evaluated at $r_{1}=c_{1}-c_{0}, \Pi_{0}^{\prime}\left(r_{1}\right)=Q^{\prime}\left(r_{1}\right)\left(P\left(Q\left(r_{1}\right)\right)-c_{0}+P^{\prime}\left(Q\left(r_{1}\right)\right) Q\left(r_{1}\right)\right)>0$, because there $Q^{\prime}\left(r_{1}\right)<0$ and, by the assumption of a non-drastic technology, $P\left(Q\left(r_{1}\right)\right)-c_{0}+P^{\prime}\left(Q\left(r_{1}\right)\right) Q\left(r_{1}\right)<0$.

${ }^{7}$ If one relaxes the non-negativity constraints and permits negative royalty rates (as long as they do not drive out the competitor), the optimal royalty rate is even negative, unless demand is linear and $n=2$.
} 
2) If firm $i$ rejects, then in the second round the licensor makes the take-it-or-leave-it offer $\left(r_{j}, f_{j}\right)$ to firm $j$; if that offer is also rejected, no licensing occurs.

Proposition 2 (Optimal two-stage dynamic mechanism). The optimal two-stage dynamic mechanism prescribes pure fixed-fee contracts: $\left(r_{i}^{*}, f_{i}^{*}\right)=\left(0, \pi_{i}\left(c^{i}\right)-\pi_{i}\left(c^{j}\right)\right)$ (first-round offer) and $\left(r_{j}, f_{j}\right)=\left(0, \pi_{j}\left(c^{j}\right)-\pi_{j}\left(c^{0}\right)\right)$ (second round offer).

These offers are either made to firms $(i, j)=(n, n-1)$ or $(i, j)=\left(i^{*}, n\right)$, where $i^{*}$ maximizes $\pi_{0}\left(c^{i}\right)+\pi_{i}\left(c^{i}\right)-\pi_{i}\left(c^{n}\right)$ over all $i \notin\{0, n\}$, whichever is more profitable for the licensor.

That mechanism is more profitable for the licensor than the optimal take-it-or-leave-it mechanism.

Proof. In two steps: 1) We characterize the optimal contracts if the first offer is made to firm $i$ and the second to firm $j ; 2)$ we characterize the optimal selection of $(i, j)$.

1) Using backward induction we first consider the subgame after firm $i$ has rejected the offer and an offer is made to firm $j$. That offer can only be a take-it-or-leave-it offer. By Proposition 1 the optimal offer is a fixed-fee contract with $f_{j}=\pi_{j}\left(c^{j}\right)-\pi_{j}\left(c^{0}\right)$.

Using this result, the first offer is accepted by firm $i$ if and only if $\pi_{i}\left(c^{i}\left(r_{i}\right)\right)-f_{i} \geq \pi_{i}\left(c^{j}\right)$. Given the royalty rate, it is optimal for the licensor to set the highest possible fixed fee. Therefore,

$$
\Pi_{0}\left(r_{i}\right)=\left(P\left(Q\left(r_{i}\right)\right)-c_{0}\right)\left(q_{0}\left(r_{i}\right)+q_{i}\left(r_{i}\right)\right)-\pi_{i}\left(c^{j}\right) .
$$

This function differs from (2) only by a constant. Therefore, the optimal royalty rate $r_{i}$ is the same as that in the optimal take-it-or-leave-it contract and the optimal first-round contract is a fixed-fee contract with $f_{i}^{*}=\pi_{i}\left(c^{i}\right)-\pi_{i}\left(c^{j}\right)$.

2) From these results it follows that the licensor's payoff is equal to

$$
\hat{\Pi}_{0}=\pi_{0}\left(c^{i}\right)+f_{i}^{*}=\pi_{0}\left(c^{i}\right)+\pi_{i}\left(c^{i}\right)-\pi_{i}\left(c^{j}\right) .
$$

It follows immediately that it is optimal to make the second offer to the firm $j$ with the highest unit cost, which minimizes $\pi_{i}\left(c^{j}\right)$ and thus maximizes the implicit threat to firm $i$. Therefore, one has either $i<n, j=n$ or $i=n, j=n-1$ and the remainder follows immediately.

3) The licensor's payoff, $\hat{\Pi}_{0}$, is greater than that of the optimal take-it-or-leave-it mechanism, $\Pi_{0}$, because:

$$
\hat{\Pi}_{0}-\Pi_{0}=f_{i}^{*}-f_{i}=\pi_{i}\left(c^{i}\right)-\pi_{i}\left(c^{j}\right)-\left(\pi_{i}\left(c^{i}\right)-\pi_{i}\left(c^{0}\right)\right)=\pi_{i}\left(c^{0}\right)-\pi_{i}\left(c^{j}\right)>0 .
$$

We mention that the license is not necessarily allocated either to the most efficient or the least efficient licensee. Allocating it to the least efficient firm raises the profit of that firm more than any alternative allocation, but also lowers the profits of the other firms more. Therefore, the allocation depends on the relative strength of these effects. For example, if $n=2$ and demand is linear, allocating to firm 1 is optimal if $c^{0}=(0,1 / 11,3 / 11)$, and allocating to firm 2 is optimal if $c^{0}=(0,1 / 33,2 / 33)$.

The optimal two-stage dynamic mechanism is more profitable than the optimal take-it-or-leave-it mechanism for two reasons: because, by threatening the first responder to award the license to the competitor (rather than not allocate the license), it reduces the default payoff of the first responder to $\pi_{i}\left(c^{j}\right)$ rather than $\pi_{i}\left(c^{0}\right)$ and implements a superior allocation. 
The first feature is similar to a standard license auction. There, bidders know that if they do not win the license, someone else wins, and this reflects in bidding. Indeed, in a second-price auction, equilibrium bids keep bidders indifferent between winning and losing in the worst-case scenario when the price is equal to the winner's bid.

\section{Generalization: Globally optimal licensing}

If there are $n \geq 2$ potential licensees, the licensor may award more than one license. This raises the questions: can one improve the above two-stage dynamic licensing mechanism by issuing more than one license, what is the optimal number of licenses, and how much payoff can the licensor extract by awarding multiple licenses?

A simple way to increase the profitability for the licensor is to replace the threat of awarding the license to another competitor if the designated licensee $i$ rejects the offer by the stronger threat of awarding pure fixed fee licenses to all other potential licensees, $j \notin\{0, i\}$. This way, the licensor can increase the first-round fixed fee $i$ from $\pi_{i}\left(c^{i}\right)-\pi_{i}\left(c^{j}\right)$ to $\pi_{i}\left(c^{i}\right)-\pi_{i}\left(c^{-i}\right)$ and thus increase his payoff.

In this particular mechanism more licenses are issued only off the equilibrium path, if the designated licensee has rejected the first-round offer. However, one can further increase the licensor's payoff by making a first-round offer to all potential licensees. In fact, one can design a two-stage dynamic mechanism that extracts the maximum surplus.

At the outset we define a mechanism as "globally optimal" if it allows the licensor to appropriate the maximum industry profit through the use of two-part tariffs with linear royalties, while reducing the potential licensees payoff to the minimum level that they can assure themselves. That minimum level is the profit they earn in the worst case, when they are the only one who did not get a license, while all rival firms operate at the lowest effective unit cost $c_{0}$. Stated formally:

Definition. A mechanism is "globally optimal" (in the class of two-part tariff mechanisms that influence outputs only indirectly, by charging output dependent royalties), if the licensor's payoff, $\Pi_{0}$, is equal to

$$
\Pi_{0}^{*}=\max _{r \in R}\left(P(Q(c(r)))-c_{0}\right) Q(c(r))-\sum_{i \in N} \pi_{i}\left(c^{-i}\right) .
$$

There $c^{-i}:=\left(c_{0}, \ldots, c_{0}, c_{i}, c_{0}, \ldots, c_{0}\right)$ denotes the cost profile in which each except the $\mathrm{i}$-th component is equal to $c_{0}$ and the i-th component is equal to $c_{i}$. This cost profile is the least profitable for firm $i \in N$, among all subsidy free cost profiles.

Consider the following two-stage dynamic mechanism where the allocation of licenses is contingent upon the acceptance decisions of all potential licensees:

$1)$ in the first-round the licensor offers contracts $\left(r_{i}, f_{i}\right)$ to all $n$ potential licensees. These contracts are applied if and only if all licensees accept. If no one accepts, no licensing occurs.

2) If a true subset $A \varsubsetneqq\{1, \ldots, n\}$ of potential licensees accepts, the licensor makes a new, secondround take-it-or-leave-it offer $\left(r_{i}^{\prime}, f_{i}^{\prime}\right)$ to all $i \in A$ and no offer to all those who rejected the firstround offer.

Proposition 3 (Globally optimal mechanism). The following two-stage dynamic mechanism awards licenses to all potential licensees and extracts the maximum surplus $\Pi_{0}^{*}$; hence, it is globally opti- 
mal:

$$
\begin{gathered}
\left(r_{i}, f_{i}\right)=\left(c_{i}-c_{0}, \pi_{i}\left(c^{0}\right)-\pi_{i}\left(c^{-i}\right)\right), \quad(\text { first-round offers }) \\
\left(r_{i}^{\prime}, f_{i}^{\prime}\right)=(0,0), \quad(\text { second-round offers }) .
\end{gathered}
$$

Proof. In two steps: 1) Using backward induction, we show that it is a dominant strategy to accept the initial offer, for all royalty rates $0 \leq r_{i} \leq c_{i}-c_{0}$. 2) We show that the stated mechanism is globally optimal.

1) Suppose some licensee(s) rejected the first offer. It is obviously a dominant strategy for all those who accepted the first offer to accept the second offer.

Consider a potential licensee $i$. If someone else rejects the first offer, it is optimal for $i$ to accept the first offer and get the license for free in the second round. If everyone else accepts the first offer and $i$ rejects, by the above argument, the payoff of $i$ is equal to $\pi_{i}\left(c^{-i}\right)$, whereas if $i$ accepts, his payoff is equal to $\pi_{i}(c(r))-f_{i}$. Because $f_{i}=\pi_{i}(c(r))-\pi_{i}\left(c^{-i}\right)$ it is a dominant strategy to accept the first offer. ${ }^{8}$

2) Substituting the fixed fees one finds that the licensor's payoff is equal to the industry profit minus a constant:

$$
\Pi_{0}(r)=\left(P(Q(c(r)))-c_{0}\right) Q(c(r))-\sum_{i \in N} \pi_{i}\left(c^{-i}\right) .
$$

It only remains to be shown that the royalty rates $r_{i}=c_{i}-c_{0}$ maximize $\Pi_{0}(r)$ over the set $R$.

Using a procedure similar to the proof of Proposition 1 and Appendix A, one finds:

$$
\begin{aligned}
Q(c(r)) & \equiv \frac{(n+1)\left(P(Q(c(r)))-c_{0}\right)-\sum_{i \in N} r_{i}}{-P^{\prime}(Q(c(r)))} \\
\partial_{r_{i}} Q(c(r)) & =\frac{1}{(n+2) P^{\prime}(Q(c(r)))+P^{\prime \prime}(Q(c(r))) Q(c(r))}<0 .
\end{aligned}
$$

Using these results we now show that $\partial_{r_{i}} \Pi_{0}(r)>0$, for all $r$ that satisfy the constraints $r_{i} \leq c_{i}-c_{0}$ :

$$
\begin{aligned}
\partial_{r_{i}} \Pi_{0}(r) & =\partial_{r_{i}} Q(c(r))\left(P(Q(c(r)))+P^{\prime}(Q(c(r))) Q(c(r))-c_{0}\right) \\
& =-\partial_{r_{i}} Q(c(r))\left(n P(Q(c(r)))-\sum_{i \in N}\left(c_{0}+r_{i}\right)\right) \quad(\text { by }(7)) \\
& =-\partial_{r_{i}} Q(c(r)) \sum_{i \in N}\left(P(Q(c(r)))-\left(c_{0}+r_{i}\right)\right) \\
& >0 \quad(\text { by (8)). }
\end{aligned}
$$

Therefore, the optimal solution is $r_{i}=c_{i}-c_{0}$ and we conclude that the stated mechanism is globally optimal.

If this mechanism is applied, each potential licensee is charged the maximum permitted royalty rate equal to its cost reduction together with a positive fixed fee. As a result, licensing makes all potential licensees worse off than prior to licensing. This is compatible with voluntary participation because the first offer is contingent upon its acceptance by all potential licensees, and the second-round license contract penalizes all those who rejected the first-round contract by awarding a free license to all those who accepted the first offer.

\footnotetext{
${ }^{8}$ One can easily make it a strictly dominant strategy by making $f_{i}$ slightly smaller.
} 
We mention that the extreme threat of awarding a free license to all those who accepted the firstround offer can be softened by awarding pure fixed fee licenses. However, like in other areas of the mechanism design literature, it is essential that the licensor is able to commit to execute the announced mechanism.

The proposed mechanism is inspired by the "chutzpah" mechanism introduced by Kamien, Tauman, and Zamir (1990) and adapted to licensing problems by Kamien, Oren, and Tauman (1992, Section 7). However, the proposed mechanism is superior.

Proposition 4. The proposed mechanism is more profitable for the licensor than the "chutzpah" mechanism.

Proof. To characterize the payoff that the licensor earns in the chutzpah mechanism, let $A \subseteq N$ denote the subset of firms who are given access to the technology with $\operatorname{cost} c_{0}$. Also, define $c^{A}$ as:

$$
c_{i}^{A}=\left\{\begin{array}{lll}
c_{0} & \text { if } & i \in A \\
c_{i} & \text { if } & i \notin A .
\end{array}\right.
$$

As is well-known, the chutzpah mechanism yields the following payoff of the licensor: ${ }^{9}$

$$
\max _{A \subseteq N} \sum_{i \in N}\left(P\left(Q\left(c^{A}\right)\right)-c_{i}^{A}\right) q_{i}\left(c^{A}\right)-\sum_{i \in N} \pi_{i}\left(c^{-i}\right) .
$$

Now, suppose $A$ is the optimal subset in the chutzpah mechanism. Consider the particular vector of royalty rates $r^{\prime}$ with $r_{i}^{\prime}=0$ for $i \in A$ and $r_{i}^{\prime}=c_{i}-c_{0}$ for $i \notin A$. Then,

$$
\begin{aligned}
\max _{r \in R} \Pi_{0}(r) & \geq \Pi_{0}\left(r^{\prime}\right) \\
& =\left(P\left(Q\left(c\left(r^{\prime}\right)\right)\right)-c_{0}\right) Q\left(c\left(r^{\prime}\right)\right)-\sum_{i \in N} \pi_{i}\left(c^{-i}\right) \\
& \geq \sum_{i \in N}\left(P\left(Q\left(c\left(r^{\prime}\right)\right)\right)-c_{i}^{A}\right) q_{i}\left(c\left(r^{\prime}\right)\right)-\sum_{i \in N} \pi_{i}\left(c^{-i}\right) .
\end{aligned}
$$

If $A=N$ the first inequality is strict by (9) and if $A \neq N$ the second inequality is strict. Therefore, at least one of the inequalities is strict and we conclude that the proposed mechanism is more profitable for the licensor than the chutzpah mechanism.

Essentially, the proposed mechanism is superior to the chutzpah mechanism because it employs royalty rates to control outputs that generates a higher extractable surplus. The use of royalties was not considered in Kamien, Oren, and Tauman (1992) because they assumed that outputs cannot be observed by the licensor.

We close with a brief extension.

So far we assumed that awarding licenses to some firms will never crowd out any firm that is not awarded a license. We now relax this assumption.

Proposition 5. Suppose it is possible to drive out some firm(s) by awarding the license to a subset of firms. It is nevertheless optimal to award licenses to all firms and apply the "globally optimal" mechanism stated in Proposition 3.

\footnotetext{
${ }^{9}$ In the literature, the chutzpah mechanism has been applied to a symmetric model with an outside innovator. We have adapted it to the present asymmetric framework with an inside innovator.
} 
Proof. Suppose, per absurdum, that one can improve the above stated globally optimal mechanism by awarding licenses to a subset of firms $S \subset N$ and crowd out some firm(s). Denote the set of firms that are active by $T \subset N$. Then a firm, $i \notin T$, is also driven out in the worst case when all other firms are awarded the technology at zero royalty rates. Therefore, $\pi_{i}\left(c^{-i}\right)=0$, for all $i \notin T$. If the alternative mechanism is applied, the licensor's payoff is bounded from above, as follows:

$$
\begin{aligned}
\sum_{i \in S \cup\{0\}}\left(P(Q)-c_{0}\right) q_{i}-\sum_{i \in S} \pi_{i}\left(c^{-i}\right) & \leq \sum_{i \in T \cup\{0\}}\left(P(Q)-c_{0}\right) q_{i}-\sum_{i \in T} \pi_{i}\left(c^{-i}\right) \\
& =\left(P(Q)-c_{0}\right) Q-\sum_{i \in N} \pi_{i}\left(c^{-i}\right) \\
& \leq\left(P\left(Q\left(c^{0}\right)\right)-c_{0}\right) Q\left(c^{0}\right)-\sum_{i \in N} \pi_{i}\left(c^{-i}\right) \\
& =\Pi_{0}^{*} \quad \text { (by (3) ). }
\end{aligned}
$$

There, the first inequality follows from the fact that $\left(P(Q)-c_{0}\right) q_{i} \geq \pi_{i} \geq \pi_{i}\left(c^{-i}\right)$ for all $i \in T \backslash S$; the equality in the second line follows because $\pi_{i}\left(c^{-i}\right)=0$ for all $i \notin T$; and the last inequality follows from the fact that $\left.\left(P(Q)-c_{0}\right)\right) Q$ is decreasing in $Q$ (because $Q$ exceeds the monopoly output) and $Q>Q\left(c^{0}\right)$.

Therefore, the globally optimal mechanism cannot be improved even if the technology is such that one can drive out some firm(s) by awarding licenses to a subset of firms.

\section{Discussion}

The proposed globally optimal mechanism can also be adapted to the analysis of the outside innovator's licensing problem. The only difference is that one has to exclude the profit of firm 0 from the licensor's payoff $\Pi_{0}$. Because in license auctions the licensor's payoff is never greater than that achieved by the chutzpah mechanism (see Kamien, Oren, and Tauman, 1992, Proposition 8), it follows immediately that license auctions are not optimal if outputs can be observed by the licensor. ${ }^{10}$

The proposed globally optimal mechanism makes all potential licensees worse off than in the prior state without licensing. Therefore, licensees would benefit if they could collectively reject the license contracts. However, each potential licensee benefits from breaching such an agreement because accepting the agreement while all others reject it gives free access to the technology. Therefore, such an agreement is not self-enforcing.

We assumed that the firm that owns the most efficient technology engages in licensing, whereas all other firms play the role as potential licensees. This is compelling if all potential licensees have the same technology. However, if firms are asymmetric, all firms other than the least efficient one may also offer their technology to others. This indicates that, if firms are asymmetric, there are limits to how much surplus the licensor can extract from licensees. This suggests an intriguing problem for further research.

\section{A Appendix: Supplement to the proof of Proposition 1}

Here we characterize the equilibrium outputs of the oligopoly subgames which are used in the proof of Proposition 1 and easily adapted to the proof of Proposition 3.

\footnotetext{
${ }^{10}$ See also Sen and Tauman (2007) and Giebe and Wolfstetter (2008) who supplement license auctions with royalties.
} 
Suppose the license is awarded to firm $i \in N$ with royalty rate $r_{i}$. The equilibrium outputs solve the following first-order conditions:

$$
\begin{aligned}
P\left(Q\left(r_{i}\right)\right)+P^{\prime}\left(Q\left(r_{i}\right)\right) q_{0}\left(r_{i}\right)-c_{0} & =0 \\
P\left(Q\left(r_{i}\right)\right)+P^{\prime}\left(Q\left(r_{i}\right)\right) q_{i}\left(r_{i}\right)-c_{0}-r_{i} & =0 \\
P\left(Q\left(r_{i}\right)\right)+P^{\prime}\left(Q\left(r_{i}\right)\right) q_{j}\left(r_{i}\right)-c_{j} & =0 \\
Q\left(r_{i}\right)-\sum_{k \in N_{+}} q_{k}\left(r_{i}\right) & =0 .
\end{aligned}
$$

These conditions yield:

$$
\begin{array}{rlrl}
q_{0}\left(r_{i}\right) & =\frac{P\left(Q\left(r_{i}\right)\right)-c_{0}}{-P^{\prime}\left(Q\left(r_{i}\right)\right)}, & q_{0}^{\prime}\left(r_{i}\right) & =\frac{Q^{\prime}\left(r_{i}\right)\left(P^{\prime}\left(Q\left(r_{i}\right)\right)+q_{0}\left(r_{i}\right) P^{\prime \prime}\left(Q\left(r_{i}\right)\right)\right)}{-P^{\prime}\left(Q\left(r_{i}\right)\right)} \\
q_{i}\left(r_{i}\right) & =\frac{P\left(Q\left(r_{i}\right)\right)-c_{0}-r_{i}}{-P^{\prime}\left(Q\left(r_{i}\right)\right)}, & q_{i}^{\prime}\left(r_{i}\right) & =\frac{Q^{\prime}\left(r_{i}\right)\left(P^{\prime}\left(Q\left(r_{i}\right)\right)+q_{i}\left(r_{i}\right) P^{\prime \prime}\left(Q\left(r_{i}\right)\right)\right)-1}{-P^{\prime}\left(Q\left(r_{i}\right)\right)} \\
q_{j}\left(r_{i}\right) & =\frac{P\left(Q\left(r_{i}\right)\right)-c_{j}}{-P^{\prime}\left(Q\left(r_{i}\right)\right)}, & q_{j}^{\prime}\left(r_{i}\right)=\frac{Q^{\prime}\left(r_{i}\right)\left(P^{\prime}\left(Q\left(r_{i}\right)\right)+q_{j}\left(r_{i}\right) P^{\prime \prime}\left(Q\left(r_{i}\right)\right)\right)}{-P^{\prime}\left(Q\left(r_{i}\right)\right)} \\
Q\left(r_{i}\right) & =\frac{(n+1) P\left(Q\left(r_{i}\right)\right)-\left(2 c_{0}+r_{i}+\sum_{j \notin\{0, i\}} c_{j}\right)}{-P^{\prime}\left(Q\left(r_{i}\right)\right)}, \quad Q^{\prime}\left(r_{i}\right)=\sum_{k \in N_{+}} q_{k}^{\prime}\left(r_{i}\right) .
\end{array}
$$

\section{References}

Colombo, S. and L. Filippini (2015). "Patent Licensing with Bertrand Competitors". The Manchester School 83, pp. 1-16.

Creane, A., C. Y. Ko, and H. Konishi (2013). "Choosing a Licensee from Heterogeneous Rivals". Games and Economic Behavior 82, pp. 254-268.

Fan, C., B. Jun, and E. Wolfstetter (2013). "Licensing Process Innovations when Losers' Messages Determine Royalty Rates". Games and Economic Behavior 82, pp. 388-402.

- (2016). "Optimal Bid Disclosure in Patent License Auctions under Alternative Modes of Competition". International Journal of Industrial Organization 47, pp. 1-32.

- (2017). Optimal Licensing under Incomplete Information: The Case of the Inside Patent Holder. SSRN Discussion Paper, http://dx.doi.org/10.2139/ssrn.2935589.

Faulí-Oller, R., X. Gonzàlez, and J. Sandonís (2013). "Optimal Two-Part Tariff Licensing Contracts with Differentiated Goods and Endogenous R\&D”. The Manchester School 81, pp. 803827.

Giebe, T. and E. Wolfstetter (2008). "License Auctions with Royalty Contracts for (Winners and) Losers". Games and Economic Behavior 63, pp. 91-106.

Heywood, J., J. Li, and G. Ye (2014). "Per Unit vs. Ad Valorem Royalties under Asymmetric Information". International Journal of Industrial Organization 37, pp. 38-46.

Kamien, M. I., S. Oren, and Y. Tauman (1992). "Optimal Licensing of Cost-Reducing Innovation". Journal of Mathematical Economics 21, pp. 483-508.

Kamien, M. I. and Y. Tauman (2002). "Patent Licensing: The Inside Story". The Manchester School 70, pp. 7-15.

Kamien, M. I., Y. Tauman, and S. Zamir (1990). "On the Value of Information in a Strategic Conflict". Games and Economic Behavior 2, pp. 129-153.

Katz, M. and C. Shapiro (1985). "On the Licensing of Innovations". RAND Journal of Economics 16.4, pp. 504-520. 
La Manna, M. (1993). “Asymmetric Oligopoly and Technology Transfers." Economic Journal 103, pp. 436-443.

Niu, S. (2013). "The Equivalence of Profit-Sharing Licensing and Per-Unit Royalty Licensing". Economic Modelling 32, pp. 10-14.

- (2017). "Profit-Sharing Licensing". Journal of Economics, forthcoming.

Poddar, S. and U. Sinha (2010). "Patent Licensing from a High-Cost Firm to a Low-Cost Firm". The Economic Record 86, pp. 384-395.

San Martín, M. and A. Saracho (2010). "Royalty Licensing”. Economics Letters 107, pp. 284-287.

Sen, D. and Y. Tauman (2007). "General Licensing Schemes for a Cost-Reducing Innovation". Games and Economic Behavior 59, pp. 163-186.

Shapiro, C. (1985). "Patent Licensing and R\&D Rivalry". American Economic Review, Papers and Proceedings 75.2, pp. 25-30.

Wang, X. H. (1998). "Fee versus Royalty Licensing in a Cournot Duopoly Model". Economics Letters 60, pp. 55-62. 